\title{
A multicentre trial of recombinant growth hormone and low dose oestrogen in Turner syndrome: near final height analysis
}

\author{
D I Johnston, P Betts, D Dunger, N Barnes, P G F Swift, J M H Buckler, G E Butler
}

Children's

Department, University Hospital, Queen's Medical Centre, Nottingham NG7 2UH, UK

D I Johnston

Department of Paediatrics, Southampton General Hospital, Southampton, UK P Betts

Department of Paediatrics, Addenbrooke's Hospital, Cambridge, UK

D Dunger

$\mathrm{N}$ Barnes

The Children's Hospital, Leicester Royal Infirmary, Leicester, UK P G F Swift

Department of Paediatric and Adolescent

Endocrinology, Leeds General Infirmary,

Leeds, UK

J M H Buckler

G E Butler

Correspondence to: Dr Johnston

derek.johnston@

nottingham.ac.uk

Accepted 20 September 2000

\begin{abstract}
Background-Turner syndrome accounts for $15-20 \%$ of childhood usage of growth hormone (GH) in the UK but final height benefit remains uncertain. The most effective strategy for oestrogen replacement is also unclear.

Methods-Fifty eight girls who, at start of treatment, were of mean age 9.1 years and projected final height $142.2 \mathrm{~cm}$ were randomised to receive in year 1 , either low dose ethinyloestradiol 50-75 ng/kg/day, GH $28 \mathrm{IU} / \mathrm{m}^{2}$ surface area/week as a daily injection, or a combination of ethinyloestradiol and GH. After the first year, the ethinyloestradiol treated girls received combination treatment. After two years, girls aged over 12 years were given escalating ethinyloestradiol to promote pubertal development.

Results-Near final height was available for 49 girls at age 16.5 years, $146.8 \mathrm{~cm}$, representing a gain of $4.6 \mathrm{~cm}$, range -7.9 to $+11.7 \mathrm{~cm}$. Twelve of the 49 girls gaining $7.5 \mathrm{~cm}$ or more were less than 13 years at the start and had received GH for at least four years. Height gain was correlated with greater initial height deficit. Fifteen girls $(31 \%)$ reached $150 \mathrm{~cm}$ or more compared to a predicted $10 \%$. Early supplementation with ethinyloestradiol provided no final height advantage.

Conclusions-Final height gain was modest at $4.6 \mathrm{~cm}$. Younger, shorter girls gained greatest height advantage from GH. Low dosage ethinyloestradiol before planned induction of puberty was not beneficial. (Arch Dis Child 2001;84:76-81)
\end{abstract}

Keywords: Turner syndrome; growth hormone; oestrogen; final height

Short stature is an important issue for most girls with Turner syndrome (TS) but the impact of growth hormone $(\mathrm{GH})$ treatment on childhood growth and final height is uncertain. ${ }^{1}$ The availability of recombinant $\mathrm{GH}$ in the mid 1980s coincided with preliminary data supporting height gain in girls with Turner syndrome treated with supraphysiological doses of $\mathrm{GH} .{ }^{2}$ In the UK and other countries the product licence for $\mathrm{GH}$ was extended to include the treatment of TS despite lack of long term studies to confirm worthwhile advantage for final height. Other unresolved questions include the optimal age range for intervention with $\mathrm{GH}$ and potential adverse events. Parallel concerns include the cost to health services, and the impact of daily injections on girls who already carry an increased burden of emotional difficulties.

The additive effect of combined treatment with low dose anabolic agents or oestrogens also requires clarification. Short term experimental studies have suggested a bimodal effect of oestrogens on linear growth; very low dose oestrogen accelerates limb length growth, whereas higher dosage consistent with sexual maturation has a growth suppressing effect. ${ }^{3}$

This study was designed to test two main proposals. First, that sustained treatment with $\mathrm{GH}$ in the recommended dose range 28-30 $\mathrm{IU} / \mathrm{m}^{2} /$ week would result in worthwhile gain to adult height; and second, that low dose ethinyloestradiol given to girls before intended induction of puberty would have an additional growth enhancing effect.

\section{Patients and methods}

Fifty eight girls with karyotypes consistent with Turner syndrome were enrolled. Clinical and investigative review had excluded other growth limiting disorders, and none had received prior hormone therapy.

At entry the mean chronological age was 9.1 years (range 5.0-15.4); the girls closely matched the pooled European Turner syndrome height for age standards, ${ }^{4}$ the mean height standard deviation score being -0.1 (SD 0.9).

Ethical approval was given in the six centres involved, and written consent was obtained.

TREATMENT PROTOCOL

Following a minimum of six months baseline observation the girls were randomised to one of three first year treatment groups:

(1) Low dose oestrogen alone: ethinyloestradiol $1.0 \mu \mathrm{g} /$ day for age less than 10 years and $2.0 \mu \mathrm{g} /$ day for age over 10 years (approximating to $50-75 \mathrm{ng} / \mathrm{kg}$ body weight daily)

(2) Recombinant growth hormone (Genotropin, Pharmacia and Upjohn, Stockholm, Sweden) 28-30 IU $/ \mathrm{m}^{2}$ surface area/wk divided as a daily subcutaneous injection

(3) Combined ethinyloestradiol and GH.

At the end of the first year, group 1 patients were changed to combined ethinyloestradiol and GH treatment. Treatment centres had the option of stopping ethinyloestradiol therapy if girls showed unacceptable premature breast development or excessive bone age maturation.

From age 12 years girls were started on an escalating programme of oestrogen replacement starting with ethinyloestradiol $2.0 \mu \mathrm{g} /$ day 
for 12 months, $5.0 \mu \mathrm{g} /$ day for 12 months, and $10 \mu \mathrm{g} /$ day for 12 months with addition of norethisterone on a cyclical basis. The rate of further oestrogen dose increment was guided by staging of breast development and ultrasound evidence of uterine growth.

The treatment intention was to continue growth hormone treatment until height increase had fallen below $1 \mathrm{~cm} /$ year.

PATIENT MONITORING

Standing height, sitting height, and weight were measured at three to six monthly intervals. Height standard deviation scores (HSDS) were derived from published Turner height stand$\operatorname{ards}^{4}$ :

\section{(observed height \\ Height SDS $=\frac{- \text { Turner height mean for age) }}{\text { SD }}$}

The HSDS at start of treatment was used to derive predicted final height on the assumption that girls with TS have close relations between height in the first decade and adult height. ${ }^{4}$ According to this Lyon height projection model, a girl with a starting HSDS -0.1 would be expected to have a final HSDS of -0.1 . The historical mean final height, $143 \mathrm{~cm}$, is derived from TS young women at age 20 years.

Near final height was defined as the height achieved at the end of a 12 month observation period during which height gain had been less than $1.0 \mathrm{~cm}$. Parental HSDS values were calculated using normal population data. ${ }^{5}$

Bone age (BA), initially determined at yearly intervals, was calculated using the TannerWhitehouse RUS (radius, ulna and finger (or short) bones) method applicable to a normal female population. ${ }^{6}$ Pubertal staging was performed using Tanner-Whitehouse standards.

The following laboratory investigations were performed before entry and annually: full blood count; fasting blood sugar, triglycerides, and cholesterol; HbA1c; electrolytes, creatinine, liver function tests, free thyroxine, thyroid stimulating hormone, luteinising hormone, and follicle stimulating hormone. GH provocation tests were performed prior to entry; peak $\mathrm{GH}$ responses are reported but did not qualify patients for entry to this study.

STATISTICAL ANALYSIS

Results are expressed as mean/median (range) or mean (SD). Within group results were com-

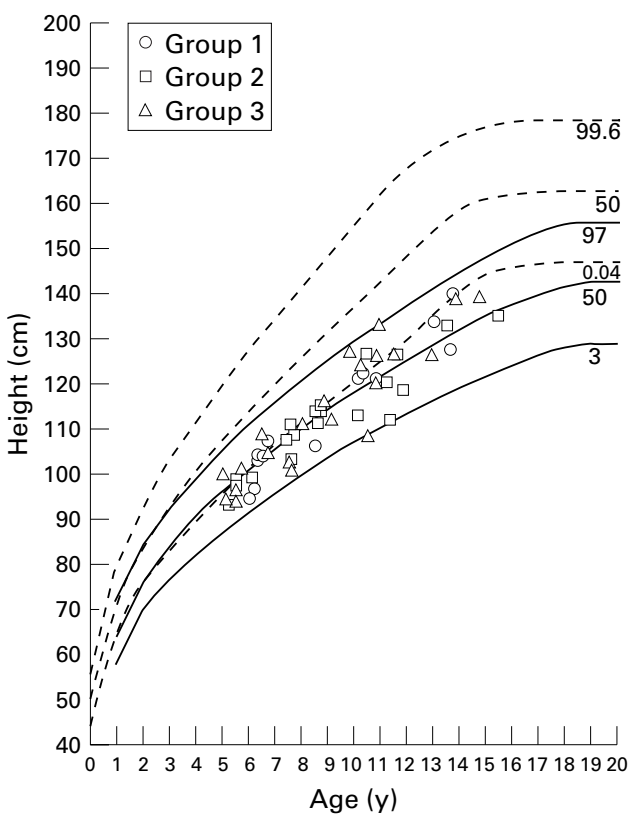

Figure 1 Heights at start of study, plotted on Turner standard charts derived from the data of Lyon, Preece, and Grant (1985) compared to the UK normal reference (1990). The solid curves represent the 3rd, 50th, and 97th centiles for Turner girls. The broken curves represent the 0.4 th, 50th, and 99.6th centiles for normal girls.

pared using the paired Student's $t$ test. Between group results were compared using analysis of variance. Simple and multiple regression analysis was performed on variables likely to influence final height and gain in height

\section{Results}

Fifty eight girls entered the study at mean chronological age 9.1 (2.8) years, and with heights matching published Turner standards, mean HSDS -0.1 (0.9) (fig 1). This value matched the mean parental HSDS of -0.1 (1.0) using normal population standards. Table 1 presents the characteristics of girls within the three treatment groups. The groups were similar for the main monitoring parameters.

All three groups showed a significant change in HSDS during the first year: group $1,+0.4$ (0.9); group $2,+0.7(0.7)$; and group $3,+1.0$ $(0.9)$. The changes in groups 2 and 3 were significantly greater than in group $1(\mathrm{p}<0.05)$. All groups sustained further increase in HSDS until the end of year 5 after which mean values in reducing numbers of girls levelled off: group

Table 1 Baseline data

\begin{tabular}{lllll}
\hline & Group 1 & Group 2 & Group 3 & $\begin{array}{c}\text { ANOVA analysis } \\
\text { between groups }\end{array}$ \\
\hline First year treatment & EO & GH & GH\&EO & GH\&EO \\
Subsequent treatment & GH\&EO & GH & 23 & NS \\
Number & 13 & 22 & $9.1(5.0$ to 14.7$)$ & NS \\
Age (y) & $9.1(6.0$ to 13.7$)$ & $9.0(5.2$ to 15.4$)$ & $8.1(3.0$ to 12.9$)$ & NS \\
Bone age (y) & $7.9(3.0$ to 13.7$)$ & $8.0(3.3$ to 13.5$)$ & $114.9(93.6$ to 139.2$)$ & NS \\
Height (cm) & $114.0(94.6$ to 140.0$)$ & $113.2(93.2$ to 135.1$)$ & $0.1(-2.2$ to +1.8$)$ & NS \\
HSDS for CA & $-0.1(-1.5$ to +1.8$)$ & $-0.3(-2.1$ to +1.2$)$ & $0.8(-1.6$ to +2.7$)$ & NS \\
HSDS for BA & $1.0(-0.6$ to +2.4$)$ & $0.6(-0.8$ to +3.3$)$ & $22.3(2.8$ to 60.0$)$ & $0.7(1.1)$ \\
GH peak (mIU/l) & $27.8(9.5$ to 44.0$)$ & $27.0(7.9$ to 81.0$)$ & &
\end{tabular}

Results expressed as mean (range) or (SD).

*Oestrogen introduced after age 12 years.

EO, ethinyloestradiol; GH, growth hormone; GH\&EO, combined treatment; CA, chronological age; BA, bone age; HSDS, height standard deviation score; NS, not significant. 
Table 2 Final height data

\begin{tabular}{|c|c|c|c|c|}
\hline & Group 1 & Group 2 & Group 3 & $\begin{array}{l}\text { ANOVA analysis } \\
\text { between groups }\end{array}$ \\
\hline Start number & 13 & 22 & 23 & \\
\hline Final number & 12 & 17 & 20 & \\
\hline Study duration (y) & 6.6 & 5.3 & 5.1 & NS \\
\hline $\begin{array}{l}\text { GH duration }(y) \\
\text { Range }\end{array}$ & $\begin{array}{l}5.6(2.5) \\
(2 \text { to } 9)\end{array}$ & $\begin{array}{l}5.3(2.1) \\
(1 \text { to } 10)\end{array}$ & $\begin{array}{l}5.1(1.6) \\
(1 \text { to } 7.3)\end{array}$ & NS \\
\hline $\begin{array}{l}\text { Age at near final height (y) } \\
\text { Range }\end{array}$ & $\begin{array}{l}16.7(1.4) \\
(14.6 \text { to } 19.8)\end{array}$ & $\begin{array}{l}16.3(1.4) \\
(14.5 \text { to } 19.2)\end{array}$ & $\begin{array}{l}16.4(1.3) \\
(13.6 \text { to } 19.3)\end{array}$ & NS \\
\hline $\begin{array}{l}\text { Near final height }(\mathrm{cm}) \\
\text { Range }\end{array}$ & $\begin{array}{l}145.5(4.6) \\
(138.0 \text { to } 152.3)\end{array}$ & $\begin{array}{l}146.2(5.3) \\
(137.1 \text { to } 155.3)\end{array}$ & $\begin{array}{l}148.2(4.6) \\
(136.6 \text { to } 155.2)\end{array}$ & NS \\
\hline $\begin{array}{l}\text { Predicted final height }(\mathrm{cm})^{\star} \\
\text { Range }\end{array}$ & $\begin{array}{l}142.3(6.0) \\
(133.0 \text { to } 155.1)\end{array}$ & $\begin{array}{l}141.3(5.1) \\
(128.9 \text { to } 151.0)\end{array}$ & $\begin{array}{l}143.5(6.9) \\
(128.3 \text { to } 155.1)\end{array}$ & $1<3$ \\
\hline $\begin{array}{l}\text { Height gain }(\mathrm{cm}) \text { compared to } \\
\text { predicted final height } \\
\text { Range }\end{array}$ & $\begin{array}{l}3.2(3.8) \\
(-3.7 \text { to }+9.6)\end{array}$ & $\begin{array}{l}4.9(4.9) \\
(-7.9 \text { to }+11.7)\end{array}$ & $\begin{array}{l}4.7(4.2) \\
(-3.8 \text { to }+11.4)\end{array}$ & NS \\
\hline
\end{tabular}

Results expressed as mean (SD)

^Derived from age 20 historical standards.

NS, not significant. Probability values refer to intragroup comparison.

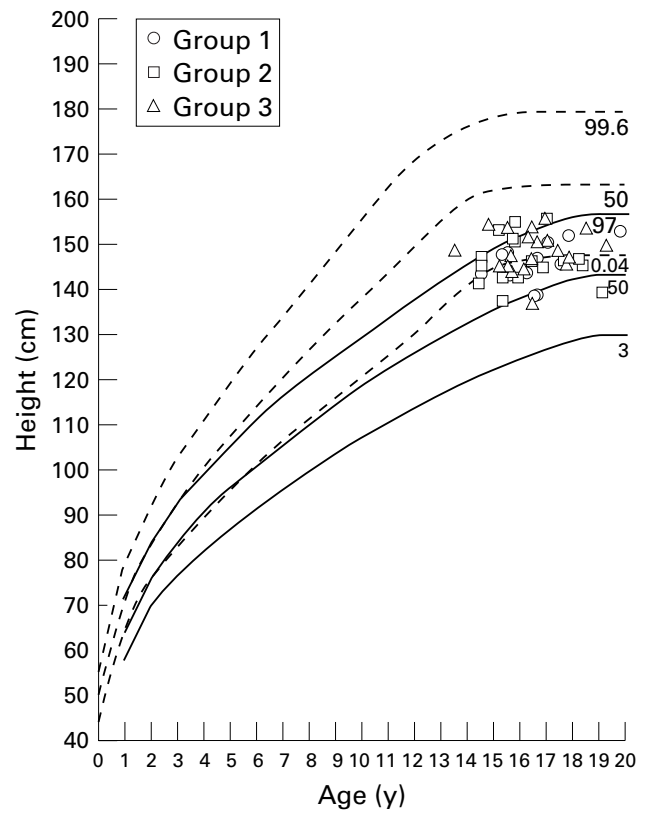

Figure 2 Heights at end of study, plotted on Turner standard charts derived from the data of Lyon, Preece, and Grant (1985) compared to UK normal reference (1990). The solid curves represent $3 \mathrm{rd}$, 50th, and $97 \mathrm{th}$ centiles for Turner girls. The broken curves represent $0.4 \mathrm{th}$, 50th, and 99.6th centiles for normal girls.

$1,+1.2(0.7)$; group 2, +1.6 (0.9); and group 3, $+1.8(0.9)$; there was no significant difference between groups (see table 2 and fig 2 ).

At the start, the apparent mean bone age delays were 1.2, 1.0, and 1.0 years for groups 1 , 2 , and 3 respectively. Groups 1 and 3 initially had more rapid catch up in bone age, but by four years of treatment all three groups had bone age matching chronological age.

The mean (range) age at which Tanner stage 2 breast development (B2) was detected occurred earlier in groups 1 and 3 receiving early ethinyloestradiol (11.7 (8.6-13.6) years and 11.3 (6.8-13.5) years respectively), compared to group 2 (12.5 (10.6-14.5) years) although this difference was not statistically significant. For the total study population the median age at $\mathrm{B} 2$ was 12.4 years.

FOLLOW UP DATA

Three of 58 girls ceased growth hormone treatment early because of serious health events not directly related to $\mathrm{GH}$ or ethinyloestradiol: one patient each with hypertension, ulcerative colitis, and brain tumour. One patient in group 3, aged 15.8 years, died from aortic dissection shortly after cessation of growth hormone treatment, having reached near final height. Compliance problems led to the withdrawal of four patients. Seven other girls developed coincidental disorders, notably thyroiditis requiring thyroxine treatment, but these were not considered sufficient to invalidate continued participation in the study

Five girls allocated to early ethinyloestradiol were converted to $\mathrm{GH}$ alone because of concern over early breast development at age range 6.2-8.9 years, or because of relative bone age advance. Oestrogen was withdrawn in one girl aged 11.7 years who subsequently sustained partial spontaneous pubertal change without exogenous oestrogen. Final height data are not available for two girls.

NEAR FINAL HEIGHT

Near final heights as judged by height velocity less than $1 \mathrm{~cm} /$ year and cessation of $\mathrm{GH}$ therapy are available for 49 girls at age 16.5 (1.34) years (range 13.6-19.8). In the absence of an effect of first year treatment on final height, the results of the whole group have been analysed together. Mean duration of GH treatment was 5.6 (2.2) years (range 1-10).

The mean near final height was 146.8 (4.9) cm (range 136.6-155.3). In comparison with TS height standards for a mean age of 16.5 years, the age at which near final heights were reached, the apparent mean height gain was 8.8 (5.6) $\mathrm{cm}$, matching an HSDS increase of 1.3 (0.8). However, historical final height standards are based on TS young women aged 20 years and adjustment for this final height standard reduced mean height gain to 4.6 (4.5) $\mathrm{cm}$ (range -7.9 to +11.7 ). By comparison with heights predicted for age 20 years, 18 of 49 girls had height gain $5 \mathrm{~cm}$ or more, and 12 had a gain $7.5 \mathrm{~cm}$ or more. Of girls gaining $7.5 \mathrm{~cm}$ or more, none were older than 13 years at start of treatment, and all received a minimum of four years of $\mathrm{GH}$.

Using the arbitrary height of $150 \mathrm{~cm}$ as a threshold for "normal stature", 15 of 49 girls (31\%) achieved this target compared with an initially predicted five $(10 \%)$. 
Analyses were performed to establish the influence of start chronological age, start BA, start HSDS, midparental HSDS, first year treatment, height response in year 1, relative $\mathrm{BA}$ advance, age at B2, and duration of $\mathrm{GH}$ treatment on final height and height gain.

Final height was significantly correlated with better initial HSDS $(r=0.5, \mathrm{p}=0.0001)$, and taller parents, midparental HSDS $(r=0.3$, $p=0.0001)$. First year treatment allocation did not influence final height.

Height gain over predicted final height for age 20 years was correlated with lower initial chronological age $(r=0.44, \mathrm{p}=0.001)$ and BA $(r=0.52, \mathrm{p}=0.0001)$ as well as shorter stature at outset, HSDS $(r=0.59$, $\mathrm{p}=0.0001)$. Height gain was also related to first year height response $(r=0.55$, $\mathrm{p}=0.0001)$ and longer duration of $\mathrm{GH}$ $(r=0.6, \mathrm{p}=0.0001)$. First year treatment and age of $\mathrm{B} 2$ did not influence final height gain.

\section{Discussion}

Despite an extensive literature describing the use of GH in girls with TS, it remains uncertain whether current treatment recommendations achieve worthwhile height advantage. Initial studies showing medium term rather than final height advantage convinced many clinicians to embark on a policy of offering GH therapy, and not surprisingly this opportunity for increased stature has been enthusiastically promoted by family support groups. One consequence is that there is limited access to final height data on contemporary groups of girls not given $\mathrm{GH}$, but treated with current oestrogen replacement regimens. It is also likely that the TS population has shown a secular trend to taller stature. In the absence of such comparison data, the majority of studies, including this one, have used historical standards. The pretreatment heights of our study group closely matched historical standards, but we have had to assume that final height standards are also appropriate, and that it is valid to make comparisons between actual final heights achieved and predicted heights derived using these standards.

We have used a relatively strict definition of near final height, a height gain of less than 1.0 $\mathrm{cm}$ over the previous 12 months. The mean age of reaching near static growth was 16.5 years. A number of other studies have reported height gain caused by $\mathrm{GH}$ as the difference between actual and predicted height at the age at which near final height was reached. A more demanding analysis for assessing the benefit of $\mathrm{GH}$ intervention is to compare near final height with predicted height had the untreated girl gone on growing until age 20 years. The latter recognises that TS girls in the era before $\mathrm{GH}$ treatment had a slow prolonged growth curve that reached a plateau after age 18 years. It would be inappropriate to attribute presumed height advantage at age 16.5 years to $\mathrm{GH}$ intervention if, without treatment, the girl might have had the compensation of an additional two years of slow growth. However, it can also be argued that the contemporary strategy of advising earlier oestrogen replacement, in order to avoid conspicuously delayed puberty, renders the shape of the historical TS growth curve invalid. In other words TS girls treated with oestrogen replacement regimens starting at age 12 to 14 years are likely to have accelerated epiphyseal fusion and reach final height before age 18 years. The current approach of offering oestrogen induced puberty at an age that matches normal peers may lead to a decrease in the late phase of height growth. ${ }^{7}$

The mean near final height advantage in this study was approximately $8 \mathrm{~cm}$ when using height prediction for age 16.5 years, but was reduced to $4.6 \mathrm{~cm}$ by comparison with age 20 years standards.

The calculation of predicted final height based on pretreatment height measurements is also a contentious issue. Shah et al have discussed the application of height prediction methods in the context of a large UK retrospective study of $\mathrm{GH}$ treated Turner girls. ${ }^{8}$ They found the Lyon projection method, as used in this study, to be the most valid of the available tools but with the reservation that the error of derivation is relatively great for individual patient calculations. Whereas the supposed population error is $\pm 2 \mathrm{~cm}$ for $95 \%$ cases, Shah et al calculated that final height projections could alter by $3 \mathrm{~cm}$ in $55 \%$ of cases followed over two years. Their analysis also showed that a contemporary untreated population of UK Turner girls had final heights matching a mean of $145 \mathrm{~cm}$ compared to that of historical controls, $143 \mathrm{~cm}$. Our cohort had start of study heights close to the Lyon standards, and a mean near final height of $146.8 \mathrm{~cm}$ compared to a projected mean of $142.2 \mathrm{~cm}$. Thirty one per cent of our cohort achieved final heights of $150 \mathrm{~cm}$ or more compared to a projected $10 \%$. In the UK retrospective study of $\mathrm{GH}$ treated TS girls, $25 \%$ reached at least $150 \mathrm{~cm}$ compared to none of age and height matched untreated peers. ${ }^{8}$

The HSDS gain of this cohort calculated against age 20 year standards was +0.7 and is close to the value, +0.6 , reported in a recent analysis of the UK KIGS database ${ }^{9}$ of 52 TS girls starting $\mathrm{GH}$ before puberty and receiving equivalent dosage $\mathrm{GH}$ for four or more years. The HSDS increments of +0.7 and +0.6 equate to actual height gains of 4.6 and $4.2 \mathrm{~cm}$ respectively. These outcomes fall short of the $8.0 \mathrm{~cm}$ height gain reported by Rosenfeld et al in a US study using $\mathrm{GH}$ alone in girls of a similar age. ${ }^{10}$ The Dutch Advisory Group on Growth Hormone has conducted several multicentre studies of GH regimens in TS girls. The earlier studies ${ }^{11}$ that recruited older girls and used $\mathrm{GH}$ doses of 24-28 IU $/ \mathrm{m}^{2} /$ week produced disappointing final height gains of approximately $3 \mathrm{~cm}$. However, recent reports ${ }^{12} 13$ of girls, recruited to start GH at age 2 to 11 years, showed that after 5.0 to 8.75 years of $\mathrm{GH}$ at a dose of $28 \mathrm{IU} / \mathrm{m}^{2} /$ week they had reached a mean final height of $158.8 \mathrm{~cm}$, representing a gain of $12.5 \mathrm{~cm}$. Higher dosage $\mathrm{GH}$ at 42 and $56 \mathrm{IU} / \mathrm{m}^{2} /$ week resulted in even greater height gains, 14.5 and $16.0 \mathrm{~cm}$ respectively.

This Dutch experience that GH treatment started in young girls can produce normalisation of height during childhood and as adults 
has provided a challenge for other treatment programmes to emulate. The early recognition of TS girls and prompt referral to centres participating in trials of GH treatment is a key factor in the effectiveness of treatment programmes. International comparisons must also take account of the greater median adult height of North European TS girls, $146.9 \mathrm{~cm}$ compared to the historical UK value, $143 \mathrm{~cm}$. It is disappointing that reported UK studies have failed to match the Dutch and US final height gains; potential explanations being later age of recruitment, less successful oestrogen replacement regimens, and unrecognised compliance problems. There is obvious scope for dealing with these potential restraints on final height outcome before embarking on treatment regimens incorporating even higher dose $\mathrm{GH}$ or additional anabolic agents. Available safety data on the international use of $\mathrm{GH}$ is reassuring, but there is concern regarding the long term metabolic implications of $\mathrm{GH}$ treatment induced hyperinsulinism, ${ }^{14}$ especially if very high dose $\mathrm{GH}$ regimens are used.

It is evident that early age of TS recognition permits longer $\mathrm{GH}$ treatment and more effective height normalisation. Further work is required to define other characteristics of TS girls likely to benefit from GH therapy. Height gain with $\mathrm{GH}$ treatment is greater for shorter girls but is not demonstrably related to phenotypic features or to whether $\mathrm{X}$ chromosome microsatellite markers denote maternal or paternal origin. ${ }^{15} \mathrm{~A}$ heavier weight for height also correlates with $\mathrm{GH}$ treatment response. ${ }^{16}$

The use of low dose oestrogen prior to the planned induction of puberty was not beneficial for final height, and raised concerns about early breast development and faster skeletal maturation. Other studies ${ }^{17}{ }^{18}$ have confirmed the relation between early oestrogen exposure and poorer height gain with $\mathrm{GH}$ treatment. A recent study, comparing the introduction of oestrogen at age 12 or 15 years, showed that duration of $\mathrm{GH}$ therapy before introduction of oestrogen is a predictor of final height, and that it is preferable in terms of height gain for oestrogen induction of puberty to be delayed. ${ }^{7}$ The Dutch experience is that low dose oestrogens can be started at a normal pubertal age without interference in the near normalisation of adult height by long term GH. ${ }^{13}$ Understanding of the role of oestrogen and $\mathrm{GH}$ in bone mineralisation in TS remains speculative, and insufficient to promote early use of oestrogen. ${ }^{19}$

\section{CONCLUSION}

This study using the recommended $\mathrm{GH}$ dose of $28-30 \mathrm{IU} / \mathrm{m}^{2} /$ week administered as a daily injection has confirmed that Turner girls show initial and medium term growth acceleration. Improved growth during early childhood and early adolescence may have a positive impact on patient and family attitude to stature and contribute to enhanced self esteem. The near final height outcomes are improved for the majority of girls, but a realistic appraisal of potential adult height suggests modest benefit.
There is however a sizeable subgroup of TS girls who benefit from achieving adult height in the lower normal range and the criteria that identify girls more likely to benefit from GH treatment need to be defined. The introduction of low dosage oestrogen before the use of puberty promoting dosage was not advantageous and may have curtailed final height benefit. There is a clear need to conduct further studies to define the optimal use of $\mathrm{GH}$ treatment and oestrogen replacement in girls with TS.

This study received financial and organisational support from Pharmacia Upjohn. DIJ was the study convenor and main author; $\mathrm{PB}$ and $\mathrm{DD}$ also participated in the production of this report. All listed authors (except GEB) were responsible for generating the study design and recruiting patients; GEB replaced JMHB following the latter's retirement from clinical practice.

1 Donaldson M. Growth hormone therapy in Turner syndrome-current uncertainties and future strategies. Horm Res 1997;48(suppl 5):35-44.

2 Rosenfeld RG, Hintz RL, Johanson AJ, et al. Three-year results of a randomized prospective trial of methionyl human growth hormone and oxandrolone in Turner syndrome. 7 Pediatr 1988;113:393-400.

3 Ross JL, Cassorla FG, Skerda MC, Valk IM, Loriaux DL, Ross JL, Cassorla FG, Skerda MC, Valk IM, Loriaux DL,
Cutler GB. A preliminary study of the effect of estrogen Cutler GB. A preliminary study of the effect of estrogen
dose on growth in Turner's syndrome. N Engl f Med 1983; 309:1104-6.

4 Lyon AJ, Preece MA, Grant DB. Growth curve for girls with Turner's syndrome. Arch Dis Child 1985;60:932-5.

5 Freeman JV, Cole TJ, Chinn S, Jones PRM, White EM, Preece MA. Cross-sectional stature and weight reference curves for the UK, 1990. Arch Dis Child 1995;73:17-24

6 Tanner JM, Whitehouse RH, Cameron N, Marshall WA, Healey MJR, Goldstein H. Assessment of skeletal maturity and prediction of adult height (TW2 method), 2nd edn. London: Academic Press, 1983.

7 Chernausek SD, Attie KM, Cara JF, Rosenfeld RG, Frane J, and the Genentech, Inc., Collaborative Study Group. Growth hormone therapy of Turner syndrome: the impact of age of estrogen replacement on final height. 7 Clin Endocrinol Metab 2000;85:2439-45.

8 Shah NS, Spoudeas HA, Rosenthal M, Brook CGD. Does treatment meaningfully increase final height in Turner syntreatment meaningfully increase final height in Turner syn-
drome? A multicentre audit study of 475 adults. In preparation.

9 Betts P, Butler GE, Donaldson MDC, et al. A decade of growth hormone treatment in girls with Turner syndrome in the UK. Arch Dis Child 1999;80:221-5.

10 Rosenfeld RG, Attie KM, Frane J, et al. Growth hormone therapy of Turner's syndrome: beneficial effect on adult height. F Pediatr 1998;132:319-24.

11 Massa G, Otten B, de Muinck Keizer-Schrama SMPF, et al. Treatment with two growth hormone regimens in girls with Turner syndrome: final height results. Horm Res 1995;43: $144-6,225-30$.

12 de Muinck Keizer-Schrama SMPF, Sas TCJ, and the Dutch Advisory Group on Growth Hormone. Growth hormone treatment regimens in girls with Turner syndrome. Acta Paediatr Suppl 1999;88:126-9.

13 Sas TC, de Muinck Keizer-Schrama SMPF, Stijnen T, et al. Normalization of height in girls with Turner syndrome after long-term growth hormone treatment: results of a randomized dose-response trial. F Clin Endocrinol Metab randomized dose-rest

14 Sas TC, de Muinck Keizer-Schrama SM, Stijnen T, Aanstoop HJ, Drop SL. Carbohydrate metabolism during long-term growth hormone $(\mathrm{GH})$ treatment and after discontinuation of $\mathrm{GH}$ treatment in girls with Turner syndrome. F Clin Endocrinol Metab 2000;85:769-75.

15 Tsezou A, Hadjiathanasiou C, Gourgiotis D, et al. Molecular genetics of Turner syndrome: correlation with clinical phenotype and response to growth hormone therapy. Clin Genet 1999;56:441-6.

16 Hofman P, Cutfield WS, Robinson EM, Clavano A, Ambler GR, Cowell C. Factors predictive of response to growth hormone therapy in Turner's syndrome. $f$ Pediatr Endocrinol Metab 1997;10:27-33.

17 Naeraa RW, Kastrup KW, Nielsen J. Treatment in Turner syndrome with a low dose of peroral $17-\beta$-estradiol alone or in combination with growth hormone. In: Hibi I, Takano $\mathrm{in}$, eds. Basic and clinical approach to Turner syndrome. K, eds. Basic and clinical approach to Tur

18 Nilsson KO, Albertsson-Wikland K, Alm J, et al. Improved final height in girls with Turner's syndrome treated with growth hormone and oxandrolone. F Clin Endocrinol Metab 1996;81:635-40

19 Beckett PR, Copeland KC, Flannery TK, Sherman LD, Abrams SA. Combination growth hormone and estrogen increase bone mineralisation in girls with Turner syndrome. Pediatr Res 1999;45:709-13. 


\section{Ibuprofen for closure of patent ductus arteriosus}

Ibuprofen may have advantages over indomethacin for closure of a patent ductus arteriosus (PDA). Although both drugs inhibit both cyclooxygenase I (COX I) and cyclooxygenase II (COX II), ibuprofen is a less potent inhibitor of COX I and, possibly for that and other reasons, has less effect on cerebral, mesenteric, and renal blood flow. In the Fetal $\mathcal{E}$ Neonatal edition of this journal (1997;76:F179-84), researchers in Belgium reported on a randomised trial involving 40 preterm infants in which ibuprofen was as effective as indomethacin but had less effect on renal function. They have now extended their observations in a larger series (Bart Van Overmeire and colleagues. New England fournal of Medicine 2000;343:674-81; see also editorial, Ibid:728-9).

A total of 148 babies (gestational ages 24-32 weeks) with respiratory distress syndrome and PDA were randomly assigned at age 2-4 days to three intravenous doses of either indomethacin $(0.2 \mathrm{mg} / \mathrm{kg} 12$ hourly) or ibuprofen $(10 \mathrm{mg} / \mathrm{kg}$ first dose, then $5 \mathrm{mg} / \mathrm{kg}$ at intervals of 24 hours). Ductal closure occurred in 49/74 (indomethacin) $v 52 / 74$ (ibuprofen) (difference not significant). Urine output was assessed by bag urine collection and was significantly lower in the indomethacin group on days 3 to 7 after birth, during which time mean serum creatinine was also significantly higher in the indomethacin group. Oliguria (urine output $1 \mathrm{ml} / \mathrm{kg}$ /hour or less) occurred in 14 babies in the indomethacin group and five in the ibuprofen group. Necrotising enterocolitis occurred in eight (indomethacin) $v$ four (ibuprofen) (not statistically significant) and babies with oliguria were significantly more likely to develop necrotising enterocolitis than those without oliguria.

In the accompanying editorial, it was pointed out that the babies in this trial were relatively mature (average 28 weeks) and the effectiveness of ibuprofen at lower gestational ages is uncertain. There is currently no suitable preparation of ibuprofen commercially available.

ARCHIVIST 